\title{
Aldabra - The Case for Conserving this Coral Atoll
} By Roger Gaymer

Aldabra, one of the few islands left in the world with a distinctive fauna undisturbed by man, is threatened with the installation of an air base and $a$ radio station that would without doubt ruin its scientific value and probably exterminate several rare, and some unique, birds. The author, a member of the Bristol University Seychelles Expedition of 1964-65, spent two months on Aldabra, which lies 630 miles south-west of Seychelles and 230 miles northwest of Madagascar. He describes some of the interesting animals and birds and the unique opportunity for scientific study that the island offers, and points to Assumption Island as a "grim warning" of what human interference can do to such an island.

ADABRA is a large coral atoll in the Indian Ocean, some 230 miles A north of Madagascar. It is far from civilisation from which it has been saved by the almost total lack of soil, drinkable fresh water or guano, which brought man to the other large islands in the Indian Ocean with disastrous results-the destruction of their forests and extinction of many animals and birds, among them the famous dodos of the Mascarene Islands, the sea cows and crocodiles of Seychelles, the flamingos of Mauritius, and the giant tortoises which once lived in huge numbers on most of the islands in the western Indian Ocean and now survive only on Aldabra. With the tortoises live many other interesting and unique animals and plants, for Aldabra lies near enough to Madagascar and the Comoro Islands for many species to have immigrated, and over thousands of years these have adapted to the strange conditions on the atoll, and in doing so have become new species.

The island presents a unique opportunity to biologists and the last chance of studying wild giant tortoises and other animals under completely natural conditions. It is one of the few islands left where there has been no interference by man, or his hosts of domestic animals, pests and weeds. Tristan da Cunha, for example, has eleven species of introduced animals and 82 introduced flowering plants, eleven of them aggressive weeds, while in Seychelles there are at least ten introduced land birds, some very successful. On Aldabra there are no introduced animals, apart from a few goats on South Island, and chickens which have run wild on Settlement Island. Moreover, not only are most of the animals on Aldabra truly native, many of them are now found nowhere else in the world.

By far the most conspicuous animal is the giant tortoise Testudo gigantea, which occurs in large numbers over most of the South Island, and to a lesser extent on North and Settlement Islands. The Bristol 


\section{SETTLEMENT}

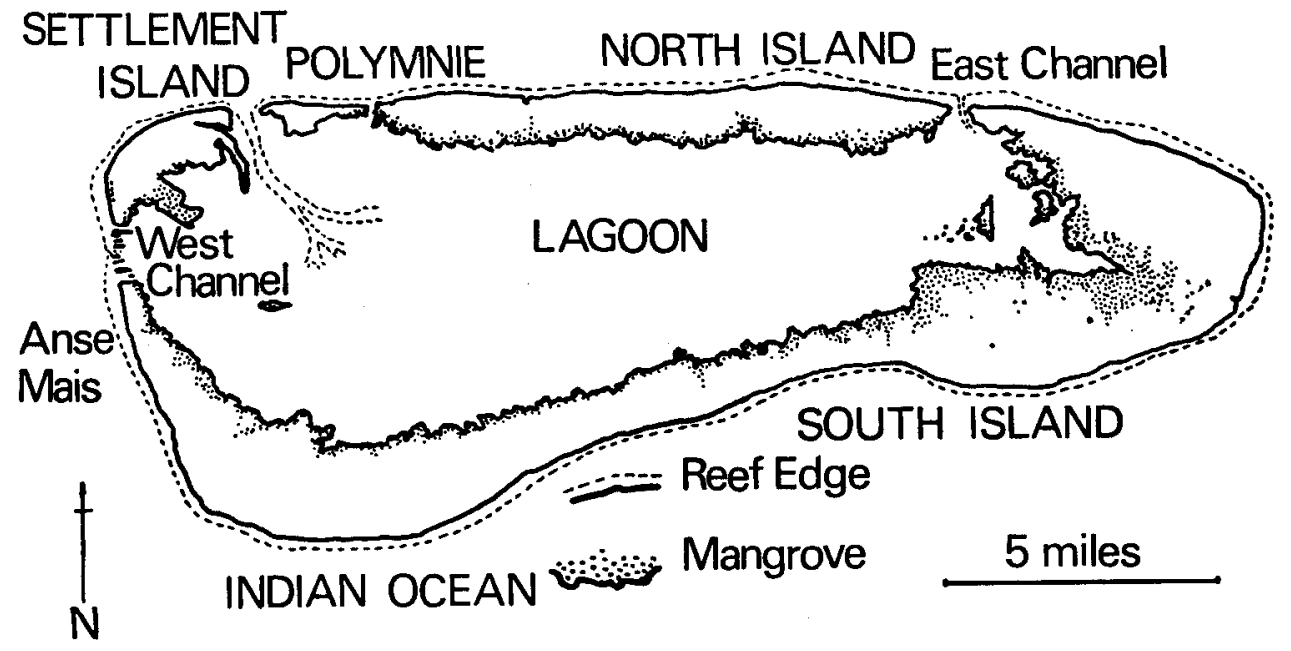

\section{ALDABRA ATOLL}

Seychelles Expedition 1964-65 estimated the total population at 33,000 , of which about 30,000 were on South Island. The contrast between this large, thriving population and the sad remnants of the Galapagos tortoises is not fully appreciated. It is not true, as has been said, that the Aldabra tortoise is near extinction and so not comparable with those of the more famous Galapagos. The Galapagos tortoises are extinct over most of their former range, and most of the survivors are in danger from introduced goats, dogs, pigs and other animals. Indeed it is questionable if any of the Galapagos populations can be regarded as entirely natural, because of the drastic effects of human colonisation; certainly none are as large and unaffected by man as those on South Island, Aldabra.

In the dry season the tortoises gather in large numbers around the few fresh water pools in the south-east, spending the heat of the day under shady trees or nearly submerged in stagnant mud. In the morning and evenings they move about, feeding on dry grasses and leaves, sometimes travelling to a pool to drink if one is within easy reach. In the wetter months like all life on Aldabra they are more active, and so probably more scattered over the island, feeding on fresh green grass and leaves, and drinking from rain-water pools.

The only other land animals are bats, lizards and a host of invertebrates. An endemic fruit bat Pteropus aldabranus might be mistaken for a bird, for it flies by day and looks like a rook; two small insectivorous bats are rarely seen. One of the lizards, the green diurnal gecko Phelsuma abbotti, is of special interest as it is often found in association with the tortoises, feeding on flies which settle on the smooth warm shell of the tortoise and hiding beneath it if alarmed. 


\section{The Land Birds}

Of the fifteen species of land birds, only two are not at least subspecies confined to Aldabra. The rather rare rail Dryolimnas cuvieri abbotti, a flightless form of a Madagascar species, is now extinct on Mauritius and Assumption, though a different subspecies may possibly survive in small numbers on Cosmoledo and Astove islands. The Aldabra population is probably the largest, but numbers only a fow hundred birds which are confined to North Island, on the few sandy beaches and among the huge sea bird colonies. It is so tame and inquisitive that it will run to investigate any strange noise, and can easily be caught in the hand. As the last surviving flightless bird of an area which once boasted the fantastic dodo, it would be sad if this rail also became extinct, as well it might.

Flamingos have long been reported on Aldabra, but specimens have only once been collected and these have not been identified. They seem to be a new subspecies of the greater flamingo Phoenicopterus ruber. About 50 birds are now known to live in the south-east, and probably breed there. There are also about a thousand sacred ibis Threskiornis aethiopica abbotti on South Island, breeding in colonies near water. The young are delightfully tame, but no longer probe for food in the shoes of visitors as once reported. The not infrequent slaughter of roosting ibis for the pot has taught them caution and fear.

The exotic midnight-blue and pale grey pigeon Alectroenas sganzini minor, another impressive bird which has become more timid since its discovery, lives on the rather sparse supply of fruit in the woodland, never coming down to the ground. The turtle dove Streptopelia picturata aldabrana is a ground feeder in the woodland, feeding in small flocks on seeds. More colourful is the male Aldabra fody or weaver Foudia aldabrana, with bright scarlet head and breast and yellow hind parts, quite outshining his hen, a dull yellowish sparrow of a bird. Other fairly common birds are the drongo Dicrurus aldabranus, a white-eye, a bulbul and a sunbird, all endemic subspecies with close relatives on the Comoros or Madagascar. Less common is the kestrel, Falco newtoni aldabranus, which feeds mainly on endemic lizards. It was seen breeding for the first time in 1964, in a coconut palm, at Anse Mais on the west coast. Three fluffy young were well protected by the parents which flew at any intruders however large.

\section{The Scientific Value}

The fact that many of these Aldabra land birds have close relatives nearby in no way decreases their interest and value. On the contrary, since many are members of a large series of forms which have a wide range, the differences between them may prove of great importance in evolutionary and ecological theory. The unaltered ecology of Aldabra permits the adaptive significance of these differences to be studied with real hope that the evolutionary changes can be understood. 
The Sea Birds

Of sea birds, the breeding colonies of frigate birds on North Island are by far the most important in the whole of the western Indian Ocean. The greater frigate bird Fregata minor aldabrensis is an Aldabra subspecies, as are the grey and little green herons, both nesting on Aldabra. Other sea birds also occur in huge numbersboobies, tropic birds, including the rarer red-tailed species, and many terns. None has been studied in any detail, and some might be found to be Aldabran forms.

Conservation So Far

Aldabra first became known for its tortoises, and when at the end of the last century the Mauritius government planned to put settlements on the island, Charles Darwin was one of many well known scientists who protested. Fortunately no settlement was ever achieved. When Aldabra became part of the British colony of Seychelles the tortoises were given some protection which has been effective more by good luck than by enforcement. In 1904 Lord Rothschild gave 1500 rupees (over 1100 ) for protection of the tortoises, but there is no record of how it was used. Now it appears to be Britain that is threatening not only the tortoises but the future of the Aldabra ecology as a whole. If present plans for an airbase and radio station are carried out, there is no doubt that the delicate balance of the island's ecology will eventually be upset, as well as being an immediate threat to the survival of many animals and plants.

The clearing of land for runways and for fuel and building materials would mean a great loss of the none too plentiful larger trees upon which much of the wildlife depends for shelter, food and breeding sites. The nearby Assumption Island is a grim warning, for the extraction of the extensive guano deposits there reduced it to a barren desert, and exterminated all the resident sea birds, including the very rare Abbott's booby, as well as the now extinct rail Dryolimnas cuvieri abbotti and white-eye Zosterops maderaspatana subsp., the turtle dove Streptopelia picturata assumptionis and probably the coucal Centropus toulou assumptionis. Only two land birds survive on Assumption now. an endemic sunbird and the ubiquitous pied crow. Most of the destruction was the result of clearance for fuel and building, as well as guano extraction, and the thoughtless slaughter of sea birds for food, greatly disturbing the colonies which deserted as a result.

The demand for food of a large labour force on Aldabra would mean the slaughter of birds, tortoises and fish in large numbers, directly endangering several species besides changing the ecological balance of sea and land and destroying the opportunity for basic research. The ibis is already eaten by the few temporary inhabitants on the island, who probably account for several dozen per year-too many for such a small population. Turtle doves are eaten but are numerous, but the rail could be seriously affected by introduced rats and cats, or even by action against the sea birds on North Island. These sea birds would 
present a serious hazard to aircraft landing and taking off. Frigate birds are very large, and the millions which nest on North Island hang for much of the time in huge spiralling columns up to many thousands of feet, circling over the length of the atoll. The only possible solution would be to destroy them at their nests by gas or similar means, which would also kill most of the rails. Tortoises which weigh up to several hundred pounds could also be a problem on a runway, and fencing sufficient to keep out $300 \mathrm{lb}$. of determined tortoise would be very expensive indeed.

The effects of aircraft noise and human presence might also be serious. The flamingos are very shy and might well desert their nesting sites, at present unknown, but probably in the south-east. Ibis desert at the least provocation, and with such a small population this could quickly bring disaster. The long term effects on other species are difficult to estimate, but the absence of many species from around the present small settlement is suggestive.

\section{The Danger of Introductions}

But perhaps the worst threat is the destruction of the native ecology by introduced plants and animals, brought in accidentally in ships and planes, or even as pets. Many species which, under natural conditions could never have reached Aldabra, would eventually replace, or coexist with, endemic forms and transform the island into the mixed assemblage of species so characteristic of inhabited islands. The most stringent precautions can only delay this process, and eventually rubbish dumps, food stores, cultivated gardens become the nuclei for repeated invasions of rats, mice, and a host of insects and other pests. Cats, dogs, and pet birds would follow to finish off what was left of the unprotected island life.

Aldabra needs total protection combined with facilities for research, so that we can make good use of the unique opportunity that it provides. An air base, which would be out of date in fifty years, would leave us with another Assumption and our descendants would only be able to say, "What an interesting place this must have been!"

\section{References}

PENNY, M. J., 1965. Bristol Seychelles Expedition, Part V. The birds of Aldabra. Animals, Vol. 7, No. 15: 409-411.

SNOW, D. W., 1964. The giant tortoises of the Galapagos Islands. Oryx, Vol. VII, No. 6 : 277-290.

SNOW, D. W., 1966. Giant tortoises. Animals, Vol. IX, No. 3: 140-142.

STREET, P., 1960. Can the giant tortoise survive? Discovery, Vol. XXI, No. 4: $158-160$.

WACE, N. M., 1966. Last of the virgin islands. Discovery, Vol. XXVII, No. 2 : $36-42$. 